\title{
The differentiation of human MSCs derived from adipose and amniotic tissues into insulin-producing cells, induced by $\mathrm{PEI} @ \mathrm{Fe}_{3} \mathrm{O}_{4}$ nanoparticles-mediated NRSF and SHH silencing
}

\author{
RUI WANG, DIANBAO ZHANG, TAO ZHANG, FENG ZHAO, \\ HONGXIN LANG, XUEWEN LIN and XINING PANG
}

\begin{abstract}
Key Laboratory of Cell Biology and Medical Cell Biology, Department of Stem Cells and Regenerative Medicine, National Health Commission of China, Ministry of Education of China, China Medical University, Shenyang, Liaoning 110122, P.R. China
\end{abstract}

Received March 11, 2018; Accepted August 6, 2018

DOI: $10.3892 /$ ijmm.2018.3827

\begin{abstract}
Type 1 diabetes involves the immunologically mediated destruction of insulin-producing cells (IPCs) in the pancreatic islet. Mesenchymal stem cells (MSCs) have the ability to differentiate into IPCs and have become the most promising means for diabetes therapy. The present study demonstrated that human adipose-derived stem cells (hADSCs) and human amniotic MSCs (hAMSCs) are able to differentiate into functional IPCs by knocking down neuronal restrictive silencing factor (NRSF) and Sonic hedgehog (SHH). In the current study, PEI@ $\mathrm{Fe}_{3} \mathrm{O}_{4}$ nanoparticles (NPs) were used to deliver NRSF small interfering (si)RNA and SHH siRNA to hADSCs and hAMSCs. Following infection with PEI@ $\mathrm{Fe}_{3} \mathrm{O}_{4}$ NPs containing NRSF siRNA and SHH siRNA, the MSCs were induced to differentiate into IPCs. Four specific genes for islet cells were expressed in the differentiated cells. These cells also produced and released insulin in a glucose-responsive manner. These findings indicated that hADSCs and hAMSCs may be induced to differentiate into IPCs via PEI@ $\mathrm{Fe}_{3} \mathrm{O}_{4}$ NP-mediated NRSF and SHH silencing.
\end{abstract}

\section{Introduction}

Type 1 diabetes is an increasing public health problem with huge economical and social burdens (1-3). The primary therapeutic method for hyperglycemia is insulin injection, but several daily injections are required for optimal glycemic

Correspondence to: Professor Xining Pang, Key Laboratory of Cell Biology and Medical Cell Biology, Department of Stem Cells and Regenerative Medicine, National Health Commission of China, Ministry of Education of China, China Medical University, 77 Puhe Road, Shenbei, Shenyang, Liaoning 110122, P.R. China

E-mail: pangnining@126.com

Key words: mesenchymal stem cells, PEI@ $\mathrm{Fe}_{3} \mathrm{O}_{4}$ nanoparticles, small interfering RNA delivery, insulin-producing cells, diabetes regulation, which is difficult to achieve (4). The application of alternative treatments, such as cell replacement therapy using $\beta$ cells, are restricted by donor shortages and immune rejection $(5,6)$; however, stem cells provide a promising strategy to reconstitute pancreatic endocrine function. Human embryonic stem cells (hESCs) are able to differentiate into all cell types, including insulin-producing cells (IPCs) $(7,8)$. Thus far, the use of these cells is burdened by the increased risk of tumor formation as well as by ethical considerations (9).

Adult stem cells, such as mesenchymal stem cells (MSCs), are multipotent cells with self-renewal capability (10). Among the MSCs, adipose MSCs (hADSCs) are easily obtained (11), and amniotic MSCs (hAMSCs) are superior due to their relatively high yield of younger cells from a naive source (12). The potential of these MSCs to differentiate into IPCs has been evaluated previously. It was previously reported that IPCs may be obtained from hADSCs using a three-stage protocol (13) or specific differentiation media (14). Additionally, hADSC differentiation into IPCs using pancreas/duodenum homeobox protein 1 (PDX-1) gene transfer has also been successfully described (15). hAMSCs have been revealed to differentiate into IPCs using stepwise differentiation protocols (16). However, the current strategy involves exogenous overexpression mediated by viruses, and its safety and stability have motivated the search for optimized methods for more efficient differentiation. Superparamagnetic iron oxide (SPIO) nanoparticles (NPs) are non-viral gene delivery reagents that have been investigated for DNA and RNA delivery, and PEI@ $\mathrm{Fe}_{3} \mathrm{O}_{4} \mathrm{NPs}$ have demonstrated promising results clinically $(17,18)$. In our recent study, PEI@ $\mathrm{Fe}_{3} \mathrm{O}_{4}$ NPs were used in the small interfering (siR)NA silencing of MSCs (19). Herein, novel reagent, $\mathrm{PEI} @ \mathrm{Fe}_{3} \mathrm{O}_{4} \mathrm{NP}$, was adopted to differentiate MSCs into IPCs.

Neuronal restrictive silencing factor (NRSF) was first recognized due to its ability to block the transcription of neuronal differentiation genes in non-neuronal cells or in neural stem cells by binding to neuron-restrictive silencer element (NRSE) (20). Target genes of NRSF associated with islet cell development have been reported $(21,22)$, including hepatocyte nuclear factor 4a (HNF4A), paired homeobox 4 (PAX4), neurogenin-3 (NGN3) and neuronal differentiation 1 (NEUROD1). 
These data suggest that the suppression of NRSF may promote islet cell development. Further studies demonstrated that the downregulation of NRSF is required for islet development $(23,24)$, but its effect is weak unless coexpressed with other key transcription factors. In addition, sonic hedgehog (SHH) signaling exerts opposite roles in neuron and pancreas development. While the expression of SHH promotes neuronal development (25), it also inhibits pancreas specification $(26,27)$.

The present study aimed to investigate whether hADSCs and hAMSCs could differentiate into IPCs using PEI@ $\mathrm{Fe}_{3} \mathrm{O}_{4}$ NP-mediated NRSF and SHH silencing, which may offer a potentially effective therapeutic approach to cell therapy for type 1 diabetes.

\section{Materials and methods}

hADSC culture. Samples from human adipose-derived tissues were obtained from The First Hospital of China Medical University (Shenyang, China), and all samples were collected following written informed consent being obtained. The present study was approved by the Ethical Committee of the First Hospital of China Medical University. Adipose tissues were washed with PBS and incubated with collagenase I (Sigma-Aldrich; Merck KGaA, Darmstadt, Germany) at $37^{\circ} \mathrm{C}$ for $30 \mathrm{~min}$. Enzyme activity was neutralized with $10 \%$ fetal bovine serum (FBS; Hyclone; GE Healthcare Life Sciences, Logan, UT, USA) at room temperature immediately, and the cells were filtered through a $70-\mu \mathrm{m}$ cell sieve and collected by centrifugation at $180 \mathrm{x}$ g for $10 \mathrm{~min}$ at room temperature. The hADSCs were cultured in Dulbecco's modified Eagle medium (DMEM)/F12 (Gibco; Thermo Fisher Scientific, Inc., Waltham, $\mathrm{MA}, \mathrm{USA})$ at $37^{\circ} \mathrm{C}$ with $5 \% \mathrm{CO}_{2}$. Once $80-90 \%$ confluence had been achieved, the cells were trypsinized and resuspended in DMEM/F12 containing 10\% FBS. hADSCs that had been passaged thrice were used for subsequent experiments.

hAMSC culture. Samples from human amnion tissues were obtained from the First Hospital of China Medical University, and all samples were collected once written informed consent was obtained. Freshly isolated amniotic membranes were washed with $0.9 \%$ saline supplemented with gentamicin and amphotericin B to remove the blood and then immersed in PBS for $10 \mathrm{~min}$ at room temperature. The amnion was transferred into $0.25 \%$ trypsin solution and incubated at $37^{\circ} \mathrm{C}$ for $30 \mathrm{~min}$; then, the supernatant was discarded, and this process was repeated three times. Enzyme activity was neutralized with 10\% FBS at room temperature immediately. Next, the amnion was incubated with PBS containing $1 \mathrm{mg} / \mathrm{ml}$ collagenase IV (Sigma-Aldrich; Merck KGaA) and $0.1 \mathrm{mg} / \mathrm{ml}$ DNase I (Takara Biotechnology Co., Ltd., Dalian, China) at $37^{\circ} \mathrm{C}$ for $1 \mathrm{~h}$, then the cells were filtered through a $70-\mu \mathrm{m}$ cell sieve and collected by centrifugation at $180 \mathrm{x} \mathrm{g}$ for $10 \mathrm{~min}$ at room temperature. The hAMSCs were cultured in DMEM/F12 supplemented with $10 \% \mathrm{FBS}$ at $37^{\circ} \mathrm{C}$ with $5 \% \mathrm{CO}_{2}$. Once $80-90 \%$ confluence had been achieved, the cells were trypsinized and resuspended in DMEM/F12 containing $10 \%$ FBS. hADSCs that had been passaged thrice were used for subsequent experiments.

Flow cytometric characterization of MSCs. Flow cytometry was used to detect MSC surface markers on the cultured cells.
The cells were trypsinized and collected in regular mesenchymal media, then centrifuged at $180 \mathrm{x}$ g for $10 \mathrm{~min}$ at room temperature. Subsequently, the cells were resuspended in PBS, and cells incubated with monoclonal phycoerythrin-conjugated antibodies directed against cluster of differentiation (CD)45 (1:100; cat. no. 368509), CD34 (1:100; cat. no. 343505), human leukocyte antigen-antigen D related (HLA-DR) (1:100; cat. no. 307605), CD90 (1:100; cat. no. 32810) and CD105 (1:100; cat. no. 323205) (all from BD Biosciences, San Jose, CA, USA) for $30 \mathrm{~min}$ on ice. The cells were washed twice with PBS and then analyzed by flow cytometry. Data were analyzed using FCS Express 6.0 software (BD Biosciences).

PEI@Fe ${ }_{3} \mathrm{O}_{4} \mathrm{NP}$-mediated siRNA transfection. In our previous study,PEI@ $\mathrm{Fe}_{3} \mathrm{O}_{4} \mathrm{NPs}$ were successfully synthesized (19).In the present study, $\mathrm{PEI} @ \mathrm{Fe}_{3} \mathrm{O}_{4} \mathrm{NPs}$ were used to deliver siRNA into MSCs. NRSF siRNA, SHH siRNA and siRNA FAM-conjoined NC (all from Shanghai GenePharma Co., Ltd., Shanghai, China) were applied to the MSCs using PEI@ $\mathrm{Fe}_{3} \mathrm{O}_{4} \mathrm{NPs}$. The following siRNA sequences were used: NRSF siRNA, 5'-GGC CUCUAAUCAACAUGAATT-3'; SHH siRNA, 5'-GGUGUA AGGACAAGUUGAATT-3'; and FAM-conjoined siRNA NC, 5'-UUGUACUACACAAAAGUACUG-3'. The weight ratio of PEI@ $\mathrm{Fe}_{3} \mathrm{O}_{4}$ NPs and siRNA was 4:1, with $6 \mu \mathrm{l} 6 \mathrm{ng} / \mathrm{ml}$ PEI@ $\mathrm{Fe}_{3} \mathrm{O}_{4}$ NPs and $2 \mu \mathrm{l} 1.5 \mathrm{ng} / \mathrm{ml}$ siRNA transfected, as previously reported (19). The MSCs were seeded in 6-well plates, and once $80 \%$ confluence was achieved, the medium was changed. The $\mathrm{PEI} @ \mathrm{Fe}_{3} \mathrm{O}_{4} \mathrm{NPs}$ were prepared and mixed with siRNA at room temperature for $30 \mathrm{~min}$, and then added to the wells. Following incubation overnight, the culture media was replaced. Cells were transfected with FAM-conjoined siRNA NC for transfection efficiency analysis. The resulting cells were analyzed by flow cytometry as aforementioned.

Prussian blue staining. The MSCs were fixed with $4 \%$ formaldehyde for $30 \mathrm{~min}$ at room temperature, washed with PBS and then immersed in a solution consisting of equal parts of $20 \% \mathrm{HCl}$ and $10 \%$ ferrocyanide for $30 \mathrm{~min}$ at room temperature, and then washed in PBS three times.

Cell viability assay. A total of $1 \times 10^{5}$ cells/well were seeded in 96-well plates and transfected with $2 \mu \mathrm{g}$ FAM-conjoined siRNA NC using PEI@ $\mathrm{Fe}_{3} \mathrm{O}_{4}$ NPs or Lipofectamine 2000 (Gibco; Thermo Fisher Scientific, Inc.) and incubated at $5 \% \mathrm{CO}_{2}$ and $37^{\circ} \mathrm{C}$ for $24-48 \mathrm{~h}$. MTT stock solution was added to each well, and the culture was continued for $4 \mathrm{~h}$. Subsequently, the culture solution in the wells was removed. DMSO was added to each well, and then the 96-well plate was agitated at a low speed for $10 \mathrm{~min}$. The absorbance of each well was measured at $570 \mathrm{~nm}$ as the optical density.

Reverse transcription-quantitative polymerase chain reaction (RT-qPCR) analysis. Total RNA was extracted from MSCs using TRIzol reagent (Invitrogen; Thermo Fisher Scientific, Inc.). The concentration of extracted RNA was determined using an ultraviolet spectrophotometer. cDNA was synthesized using PrimeScript ${ }^{\mathrm{TM}}$ RT reagent (Takara Biotechnology Co., Ltd.) according to the manufacturer's protocol. The primers used are shown in Table I, and the reactions were performed using the SYBR PrimeScript RT-PCR 
Table I. Primers for RT-qPCR analysis.

\begin{tabular}{ll}
\hline Gene name & \multicolumn{1}{c}{ Primer sequence 5'-3' } \\
\hline PDX1 & \\
Forward & ACTCCACCTTGGGACCTGTTTAGA \\
Reverse & CGAGTAAGAATGGCTTTATGGCAGA \\
Insulin & \\
Forward & GCCGCAGCCTTTGTGAA \\
Reverse & CGGGTCTTGGGTGTGTAGAAG \\
NGN3 & \\
Forward & TGCTCATCGCTCTCTATTCTTTTG \\
Reverse & GGCAGGTCACTTCGTCTTCC \\
PAX4 & \\
Forward & GGCTGTGTGAGCAAGATCCTAGGA \\
Reverse & TTGCCAGGCAAAGAGGGCTGGAC \\
NRSF & \\
Forward & ATTGAAGTTGGCTTAGTG \\
Reverse & TATGGGTAGATTCGTTGA \\
SHH & \\
Forward & GGCTGGATTCGACTGGGTCTACTA \\
Reverse & AACTTGGTGCCACCCTGCTC \\
GAPDH & \\
Forward & GCACCGTCAAGGCTGAGAAC \\
Reverse & TGGAAGACGCCAGTGGA \\
\hline
\end{tabular}

RT-qPCR, reverse transcription-quantitative polymerase chain reaction; PDX1, pancreas/duodenum homeobox protein 1; PAX4, paired homeobox 4; NGN3, neurogenin-3; NRSF, neuronal restrictive silencing factor; $\mathrm{SHH}$, sonic hedgehog.

kit (Takara Biotechnology Co., Ltd.) with an ABI 7500 Sequence Detection system (Applied Biosystems; Thermo Fisher Scientific, Inc.). The PCR thermocycling conditions were as follows: $95^{\circ} \mathrm{C}$ for $30 \mathrm{sec}$; followed by 45 cycles of $95^{\circ} \mathrm{C}$ for $5 \mathrm{sec}$ and $60^{\circ} \mathrm{C}$ for $34 \mathrm{sec}$. Each experiment was performed three times. As an internal control, levels of GAPDH were quantified in parallel with the target genes. Normalization and fold changes were calculated using the $\Delta \Delta \mathrm{Cq}$ method (28).

Western blot analysis. Cells were lysed with radio immunoprecipitation assay (Beyotime Institute of Biotechnology, Haimen, China) buffer containing a complete protease inhibitor cocktail tablet. The protein concentration was determined using a BCA protein assay. A total of $20 \mu \mathrm{g}$ protein/lane was separated using $10 \%$ SDS-PAGE and transferred to polyvinylidene difluoride membranes. The membranes were incubated with primary antibodies, including rabbit anti-NRSF (1:1,000; cat. no. 21635; Abcam, Cambridge, MA, USA), rabbit anti-SHH (1:1,000; cat. no. 22075; Cell Signaling Technology, Inc., Danvers, MA, USA) and mouse anti-GAPDH (1:5,000; cat. no. sc-47727; Santa Cruz Biotechnology, Inc., Dallas, TX, USA) overnight at $4^{\circ} \mathrm{C}$. Following incubation with goat anti-rabbit IgG horseradish peroxidase-conjugated secondary antibody (1:10,000; cat. no. sc-2004; Santa Cruz Biotechnology, Inc.) at room temperature for $1 \mathrm{~h}$, the results were visualized using Amersham ECL Prime Western Blotting Detection reagent (GE Healthcare, Chicago, IL, USA) and a Tanon-5200 chemiluminescence detection system (Tanon Science and Technology Co., Ltd., Shanghai, China). GAPDH was used as an internal control.

Immunofluorescence. Cells were washed with PBS twice, fixed with $4 \%$ paraformaldehyde for $10 \mathrm{~min}$ at room temperature and then blocked with $1 \%$ bovine serum albumin (Amresco, LLC, Solon, OH, USA) for $60 \mathrm{~min}$ at room temperature. Subsequently, cells were permeabilized with $0.1 \%$ Triton X-100 for $5 \mathrm{~min}$ at room temperature. Cells were incubated with the rabbit anti-insulin (1:1,000; cat. no. 3014S) and rabbit anti-glucagon primary antibodies (1:1,000; cat. no. 2760S) (both from Cell Signaling Technology, Inc.) at $4^{\circ} \mathrm{C}$ overnight. Subsequently, the cells were washed with PBS and incubated with the mouse anti-rabbit fluorescence-labeled secondary antibody (1:400; cat. no. SC-2359; Santa Cruz Biotechnology, Inc.) for $1 \mathrm{~h}$ at room temperature. The labeled cells were visualized under a fluorescence microscope at x10 magnification.

Glucose-stimulated insulin secretion assay. The cells were tested for insulin secretion at basal $(5.5 \mathrm{mM})$ and stimulated $(25 \mathrm{mM})$ glucose concentrations. The differentiated cells in the plates were washed with PBS and incubated in $1 \mathrm{ml}$ of serum-free DMEM containing $5.5 \mathrm{mM}$ glucose for $5 \mathrm{~h}$ at $37^{\circ} \mathrm{C}$. The media were collected and stored at $-20^{\circ} \mathrm{C}$; then, fresh media with $25 \mathrm{mM}$ glucose was added. After $5 \mathrm{~h}$ of incubation at $37^{\circ} \mathrm{C}$, the media were collected and stored. The stored media were then analyzed for insulin content using a direct human insulin ELISA kit (cat. no. KAQ1251; Invitrogen; Thermo Fisher Scientific, Inc.). Non-induced MSCs were used as controls.

Statistical analysis. Data are expressed as the mean \pm standard deviation following three independent experiments. The statistical analyses were performed using the Student's t-test or one-way analysis of variance followed by Tukey's post hoc test with GraphPad Prism 5.0 software (GraphPad Software, Inc., La Jolla, CA, USA). P $<0.05$ was considered to indicate a statistically significant difference.

\section{Results}

Characterization of the cultured MSCs from different tissues. MSCs were isolated from human adipose tissues and amnion tissues. They were expanded in a culture flask and exhibited similar fibroblast-like morphologies. The morphology of the hADSCs was longer compared with the hAMSCs, and hADSCs exhibited a shorter doubling time (Fig. 1A). The associated cells surface markers were assessed by flow cytometry to characterize isolated MSCs. All types of MSCs expressed high levels of CD105 and CD90, but negligible levels of CD34, CD45 and HLA-DR, indicating a satisfactory level of homogeneity of the MSCs in the culture (Fig. 1B).

Transfection efficiency of PEI@Fe ${ }_{3} \mathrm{O}_{4} \mathrm{NPS} / \mathrm{siRNA}$. To evaluate the transfection efficiency of the PEI@ $\mathrm{Fe}_{3} \mathrm{O}_{4} \mathrm{NPs} / \mathrm{siRNA}$ complex, fluorescence microscopy and Prussian blue staining was used. According to Prussian blue staining, more than 
A

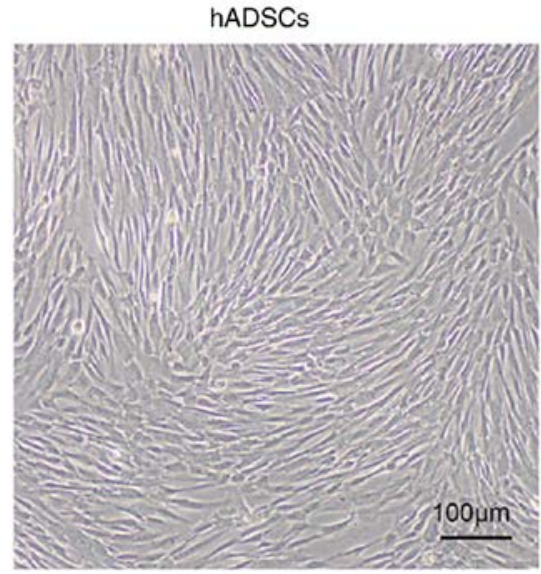

hAMSCs

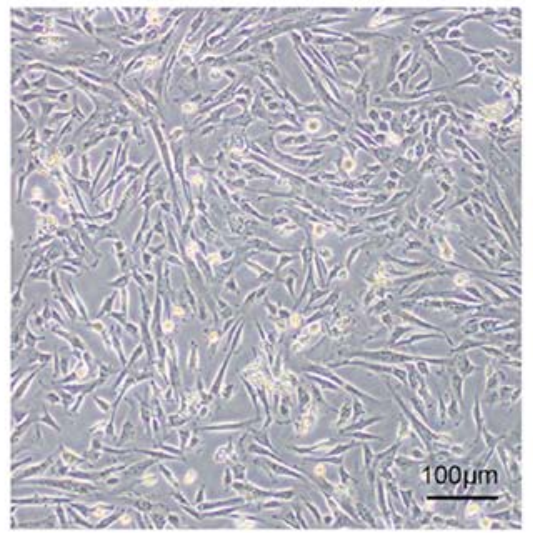

B hADSCS
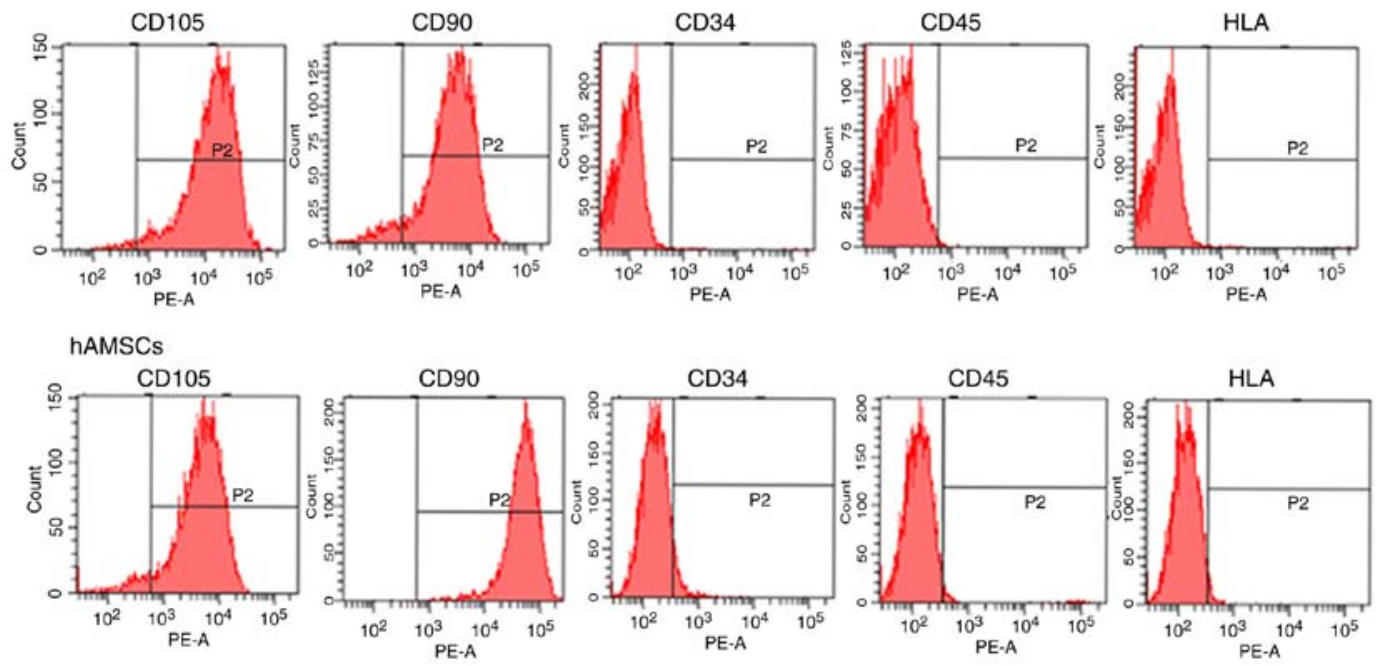

Figure 1. Characterization of the hADSCs and hAMSCs. (A) Morphology of hADSCs and hAMSCs at passage three. All cells similarly had a spindle-shaped morphology, but hADSCs adhered slightly longer compared with hAMSCs. (B) Phenotype of hADSCs and hAMSCs at passage three. The hADSCs and hAMSCs were positive for CD90 and CD105, but negative for CD34, CD45 and HLA-DR. hADSCs, human adipose-derived stem cells; hAMSCs, human amniotic mesenchymal stem cells.

A
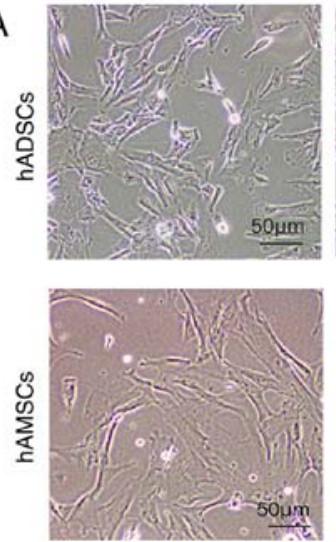
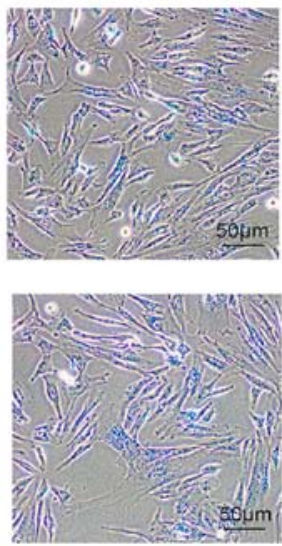

B
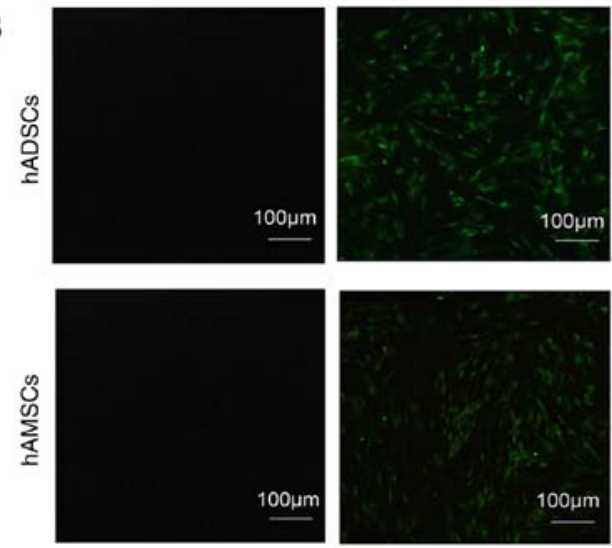

Figure 2. Transfection efficiency of the PEI@ $\mathrm{Fe}_{3} \mathrm{O}_{4}$ NPs/siRNA. MSCs incubated with 6 ng/ml concentration of PEI@Fe $\mathrm{O}_{4}$ NPs/siRNA followed by (A) Prussian staining and (B) fluorescence microscopy. MSCs, mesenchymal stem cells; hADSCs, human adipose-derived stem cells; hAMSCs, human amniotic mesenchymal stem cells; NPs, nanoparticles; siRNA, small interfering RNA.

$96 \%$ of the cells were positive (Fig. 2A). Furthermore, according to the fluorescence microscopic analysis, $>80 \%$ of the cells were FAM-positive (Fig. 2B). Thus, PEI@ $\mathrm{Fe}_{3} \mathrm{O}_{4}$ NPs were considered efficient siRNA delivery reagents in MSCs.
Comparison of the cytotoxicity of PEI@ $\mathrm{Fe}_{3} \mathrm{O}_{4} \mathrm{NPs} /$ siRNA and Lipofectamine 2000/siRNA. In addition to transfection efficiency, cytotoxicity is also an important aspect for gene delivery reagents. The majority of the non-viral delivery reagents are 


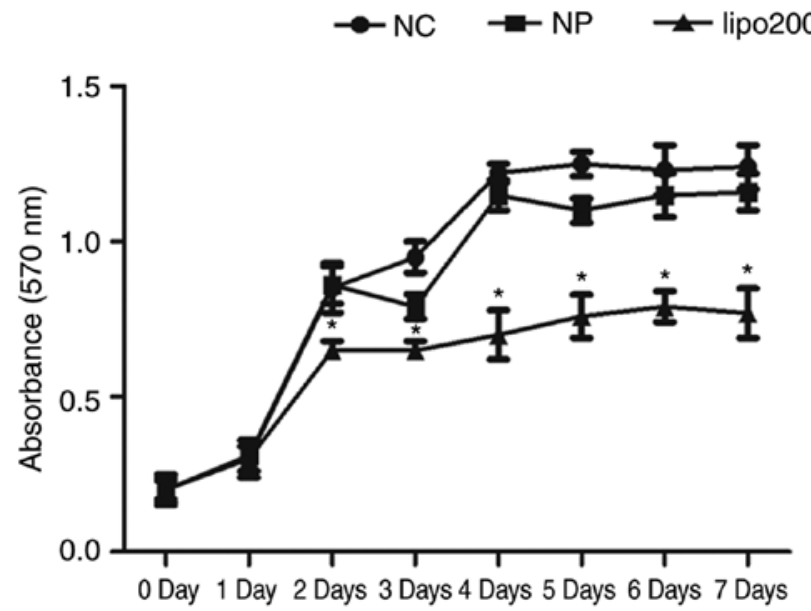

Figure 3. Cytotoxicity. Lipofectamine 2000 and PEI@ $\mathrm{Fe}_{3} \mathrm{O}_{4}$ NPs delivered small interfering RNA to the mesenchymal stem cells, as measured by MTT cell proliferation assay. Data are presented as the mean \pm standard deviation $(n=3) .{ }^{*} \mathrm{P}<0.05$. NPs, nanoparticles. nanoparticles and liposomes, and Lipofectamine 2000 is the most commonly used liposome. The present study compared the cytotoxicity of Lipofectamine 2000 with the PEI@ $\mathrm{Fe}_{3} \mathrm{O}_{4}$ NPs. As demonstrated by the MTT cell proliferation assay, the PEI@ $\mathrm{Fe}_{3} \mathrm{O}_{4}$ NPs exhibited similar activity, and Lipofectamine 2000 exhibited significantly lower activity compared with the non-transfected cells after transfection for 48 h (Fig. 3).

Expression of NRSF and SHH is downregulated in MSCs by $\mathrm{PEI} @ \mathrm{Fe}_{3} \mathrm{O}_{4} \mathrm{NPs}$. Concurrent with successful transfection, it is important to demonstrate the interference efficiency. To determine the interference efficiency of PEI@ $\mathrm{Fe}_{3} \mathrm{O}_{4} \mathrm{NPs}$ in the MSCs, RT-qPCR and western blot analysis were used to detect the expression level of NRSF and SHH in the MSCs following transfection for 2 days (Fig. 4A and B). Using western blot analysis, markedly reduced NRSF and SHH protein expression was observed in the MSCs following siRNA-targeted
A

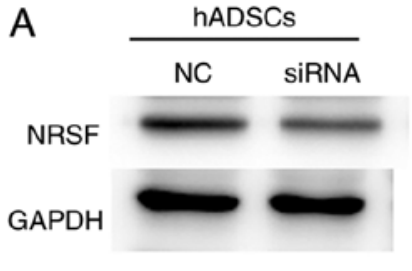

$\mathrm{SHH}$

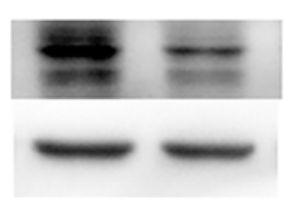

hAMSCS
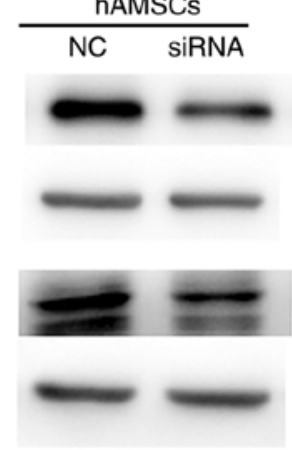

B
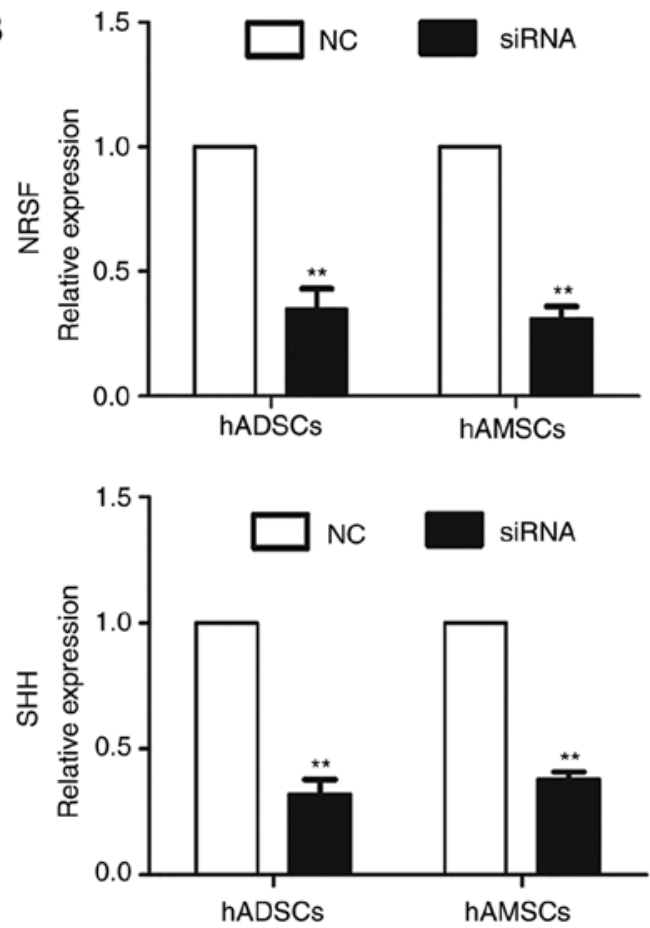

C
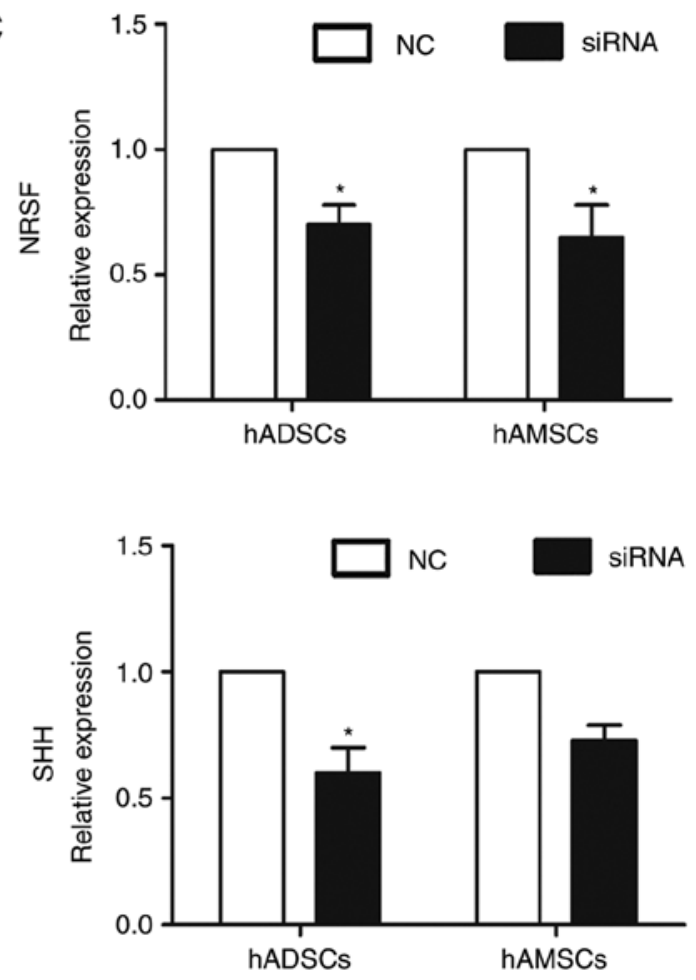

Figure 4. Interference efficiency. After 2 days of transfection, NRSF and SHH expression levels in MSCs were detected by (A) western blot analysis and (B) RT-qPCR. (C) A total of 14 days after transfection, NRSF and SHH expression levels in MSCs were detected by RT-qPCR. Data are presented as the mean \pm standard deviation $(n=3) .{ }^{*} \mathrm{P}<0.05$ and ${ }^{* *} \mathrm{P}<0.01$. RT-qPCR, reverse transcription-quantitative polymerase chain reaction. NRSF, neuronal restrictive silencing factor; SHH, sonic hedgehog; MSCs, mesenchymal stem cells; siRNA, small interfering RNA; NC, negative control; hADSCs, human adipose-derived stem cells; hAMSCs, human amniotic mesenchymal stem cells. 
A
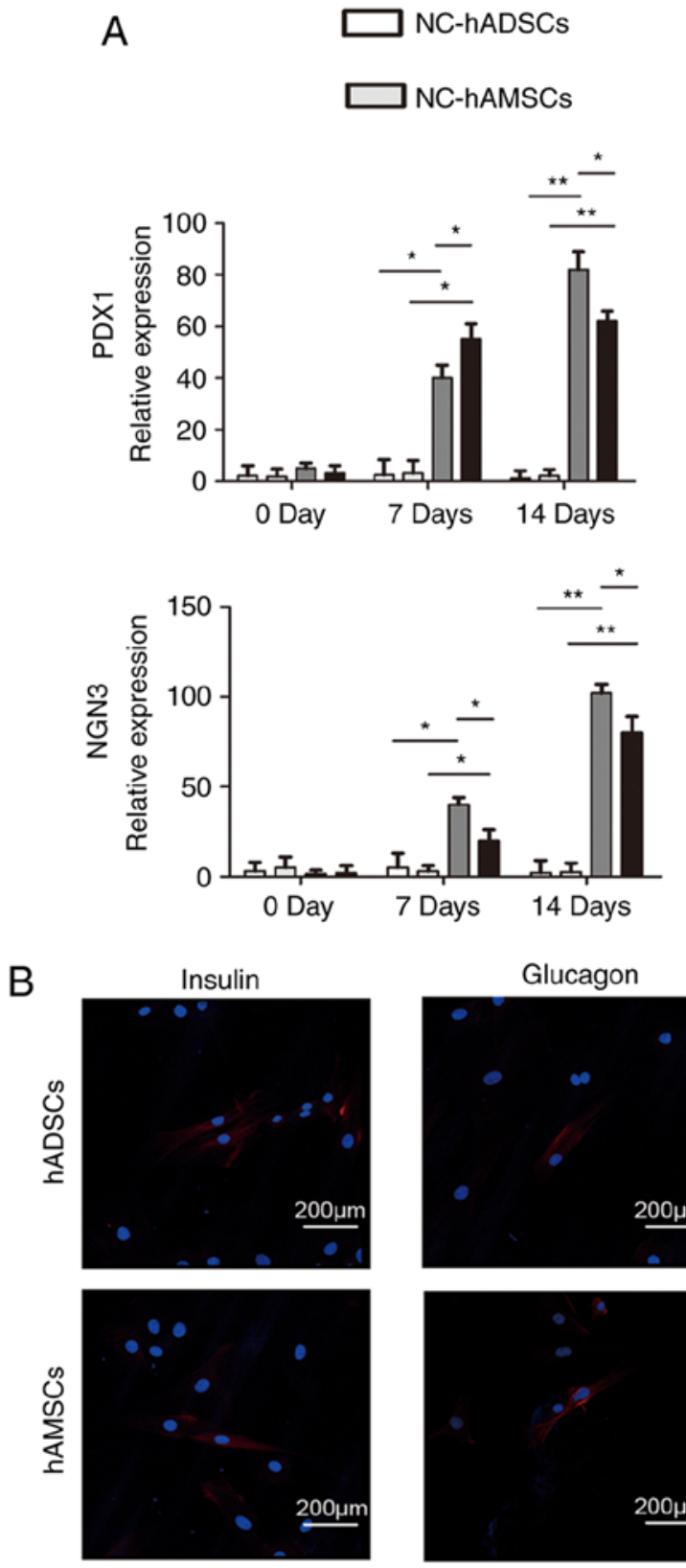
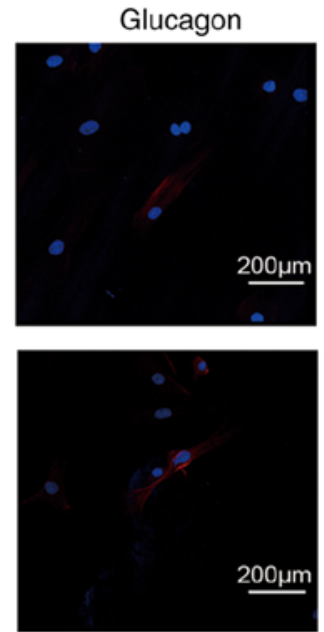

siNRSF+siSHH-hADSCs

siNRSF+siSHH-hAMSCs
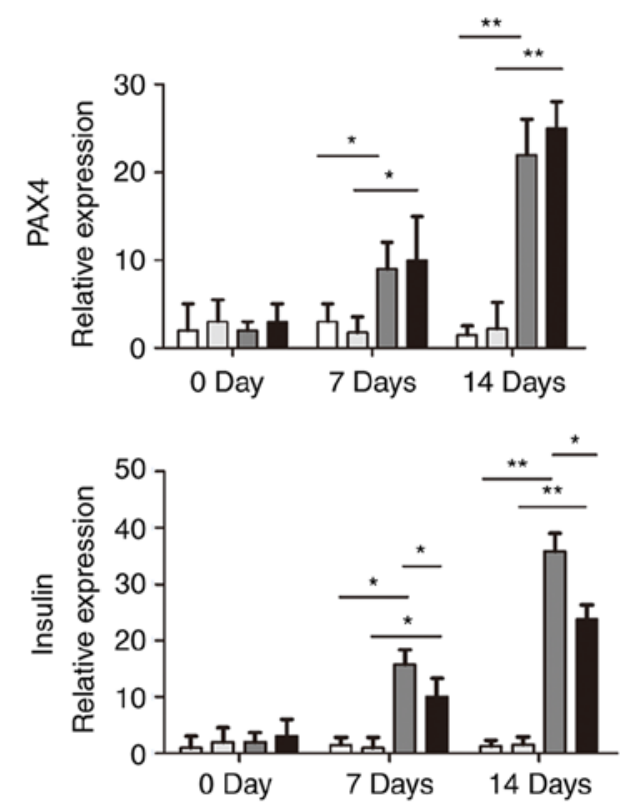

C

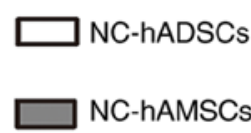

$\square$ siNRSF+siSHH-hADSCs

siNRSF+siSHH-hAMSCs

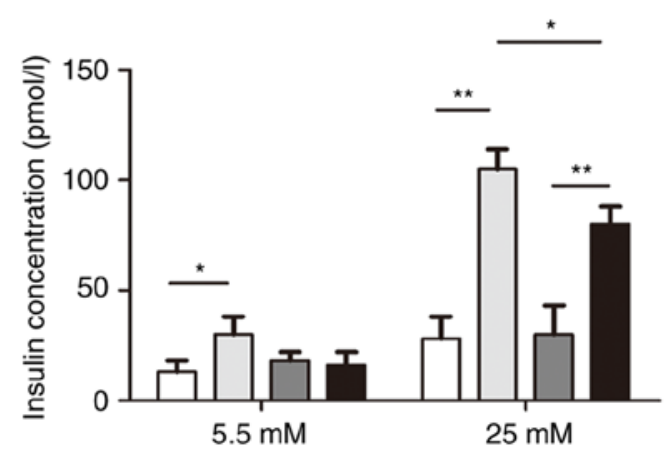

Figure 5. Detection of the islet cell-associated genes in the induced MSCs. (A) Reverse transcription-quantitative polymerase chain reaction was used to detect the insulin, PDX1, PAX4 and NGN3 in the NC (D0), and in the differentiated MSCs (D7, D14). "P<0.05 and ${ }^{* * *} \mathrm{P}<0.01$. (B) Immunofluorescence analysis for insulin and glucagon in the differentiated MSCs (D14). (C) Insulin concentrations were detected in NC and the differentiated MSCs (D14). Insulin concentrations were determined with an ultrasensitive insulin ELISA assay. Data are presented as the mean \pm standard deviation $(\mathrm{n}=3)$. ${ }^{*} \mathrm{P}<0.05$ and ${ }^{* * *} \mathrm{P}<0.01$. $\mathrm{PDX} 1$, pancreas/duodenum homeobox protein 1; PAX4, paired homeobox 4; NGN3, neurogenin-3; MSCs, mesenchymal stem cells; siRNA/si, small interfering RNA; NC, negative control; hADSCs, human adipose-derived stem cells; hAMSCs, human amniotic mesenchymal stem cells.

knockdown compared with the NC control (Fig. 4A). In addition, the mRNA level of NRSF and SHH was significantly silenced to $30 \%$ of the control in MSCs using PEI@ $\mathrm{Fe}_{3} \mathrm{O}_{4} \mathrm{NPs}$ (Fig. 4B). Furthermore, on the 14th day of the transfection, RT-qPCR was used to detect the NRSF and SHH expression levels in MSCs. The mRNA levels of NRSF and SHH were silenced to $70 \%$ of the control (Fig. 4C). These results suggested that the PEI@ $\mathrm{Fe}_{3} \mathrm{O}_{4} \mathrm{NPs}$ were highly efficient in silencing NRSF and $\mathrm{SHH}$, and the interference efficacy lasted for 14 days.

Differentiation of MSCs into IPCs. To examine whether NRSF and SHH silencing promote MSCs to differentiate into IPCs, the expression levels of several genes specific for islet cells were detected by RT-qPCR. NRSF and SHH knockdown for 7 days and 14 days significantly enhanced the islet progenitor expression of NGN3, PAX4, PDX1 and insulin compared with the NC control. The expression of these genes was significantly higher in hADSCs compared with that in hAMSCs, with the exception of PAX4 (Fig. 5A). Immunofluorescence staining was performed to detect the glucagon and insulin proteins in the induced cells following transfection for 14 days. The results demonstrated that the differentiated MSCs expressed glucagon and insulin (Fig. 5B). To determine the differentiation ability of the induced cells following transfection for 14 days, the glucose-stimulated insulin secretion 
assay was performed. The differentiated MSCs were treated with 5.5 and $25 \mathrm{mM}$ glucose, and insulin concentrations were measured using immunoassays. The induced hADSCs and hAMSCs secreted insulin, but hADSCs demonstrated a significantly increased ability to secrete insulin compared with hAMSCs following stimulation with $25 \mathrm{mM}$ glucose (Fig. 5C). In summary, the present results indicate that the induced MSCs acquired the characteristics of functional IPCs, and hADSCs exhibited a greater potential compared with hAMSCs for diabetic treatment.

\section{Discussion}

The present study investigated the differentiation of hADSCs and hAMSCs into IPCs. It was demonstrated that hADSCs and hAMSCs were able to differentiate into IPCs using $\mathrm{PEI} @ \mathrm{Fe}_{3} \mathrm{O}_{4} \mathrm{NP}$-mediated NRSF and $\mathrm{SHH}$ silencing. The differentiated MSCs exhibited elevated glucose-stimulated insulin secretory abilities. The differentiation of these MSCs into IPCs may provide an alternative renewable therapeutic strategy for diabetes treatment.

Currently, genetic delivery reagents are viral or synthetic non-viral. Although the transfection efficiency of the viral reagents is higher, there are several issues, including the induction of host immune responses and high tumorigenicity rates (29). Studies have reported MSC differentiation into IPCs using lentivirus $(23,24,30)$. The lack of reports on MSC differentiation into IPCs using non-viral gene delivery reagents led us to focus on a safer and more efficient reagent. The majority of the non-viral delivery reagents are nanoparticles and liposomes. The present study compared the cytotoxicity of liposomes with the PEI@ $\mathrm{Fe}_{3} \mathrm{O}_{4} \mathrm{NPs}$, and confirmed that PEI@ $\mathrm{Fe}_{3} \mathrm{O}_{4}$ NPs exhibited lower cytotoxicity levels and were labeled by Prussian Blue staining. This indicates that PEI@ $\mathrm{Fe}_{3} \mathrm{O}_{4} \mathrm{NPs}$ may be a better delivery reagent for cell therapy in the clinical setting. To the best of our knowledge, the present study is the first to differentiate hADSCs and hAMSCs into IPCs via NP-mediated gene silencing.

The mechanism responsible for islet cell differentiation from stem cells remains to be elucidated. During the development of islet cells, NRSF represses the human insulin gene by binding to NRSE in its promoter region (31). Several studies have demonstrated that following the downregulation of NRSF, MSCs are able to differentiate into IPCs (22.32). However, hADSCs and hAMSCs cannot differentiate into IPCs through the suppression of NRSF alone. Although SHH is not normally expressed in the pancreatic domain, a study reported that $\mathrm{SHH}$ is required for the initiation of pancreas gene expression in the posterior foregut (25). Consistently, hADSCs and hAMSCs cannot differentiate into IPCs via suppression of $\mathrm{SHH}$ alone. It has been reported that human amniotic fluid-derived stem cells are able to differentiate into IPCs using differentiation medium and the repression of NRSF (23). Cytokines in the differentiation medium have been reported to mediate the suppression of SHH signaling (23). Thus, in the present study, the combined suppression of NRSF and SHH in hADSCs and hAMSCs using PEI@ $\mathrm{Fe}_{3} \mathrm{O}_{4}$ NPs was performed. The downregulation of NRSF and SHH may trigger a derepression of NRSF- and SHH-regulated genes, subsequently promoting hADSCs and hAMSCs to differentiate into IPCs, and enhancing the islet progenitor expression of NGN3, PAX4, PDX1 and insulin. The mRNA expression of these genes was significantly higher in hADSCs compared with that in hAMSCs, with the exception of PAX4. Furthermore, hADSCs demonstrated an increased ability to secrete insulin compared with hAMSCs in a glucose-responsive manner. These data suggest that NRSF and SHH may serve dominant roles in enhancing the differentiation of the MSCs into IPCs, and that hADSCs exhibit a greater potential compared with hAMSCs for use in diabetic treatment.

In conclusion, the results of the present study demonstrated that the suppression of NRSF and SHH using PEI@ $\mathrm{Fe}_{3} \mathrm{O}_{4} \mathrm{NPs}$ may promote hADSCs and hAMSCs to differentiate into IPCs, and these differentiated cells are able to secrete insulin in response to glucose stimulation. These results support the further evaluation of the use of hADSCs and hAMSCs in cell therapy in diabetes.

\section{Acknowledgements}

Not applicable.

\section{Funding}

The present study was funded by the National Natural Science Foundation of China (grant no. 81703102), Shenyang Transformation Project of Major Scientific and Technological Achievements (grant no. Z17-5-039), Shenyang Key Laboratory Project (grant no. F15-157-1-00) and Foundation of China Medical University (grant no. XZR20160022).

\section{Availability of data and materials}

All data generated or analyzed during this study are included in this published article.

\section{Authors' contributions}

RW and DZ performed the experiments and wrote the manuscript. TZ and FZ contributed to data analysis and interpretation. HL and XL contributed to collection and assembly of data. XP designed the study and provided final approval of manuscript.

\section{Ethics approval and consent to participate}

Samples from human adipose-derived tissues and human amnion tissues were obtained from The First Hospital of China Medical University (Shenyang, China), and all samples were collected following written informed consent being obtained. The present study was approved by the Ethical Committee of the First Hospital of China Medical University.

\section{Patient consent for publication}

Not applicable.

\section{Competing interests}

The authors declare that they have no competing interests. 


\section{References}

1. Shaw JE, Sicree RA and Zimmet PZ: Global estimates of the prevalence of diabetes for 2010 and 2030. Diabetes Res Clin Pract 87: 4-14, 2010.

2. Hematti P, Kim J, Stein AP and Kaufman D: Potential role of mesenchymal stromal cells in pancreatic islet transplantation. Transplant Rev (Orlando) 27: 21-29, 2013.

3. American Diabetes Association: Standards of medical care in diabetes-2013. Diabetes Care 36 (Suppl 1): S11-S66, 2013.

4. Larrañaga A, Docet MF and Garcia-Mayor RV: Disordered eating behaviors in type 1 diabetic patients. World J Diabetes 2 : 189-195, 2011.

5. Ryan EA, Paty BW, Senior PA, Bigam D, Alfadhli E, Kneteman NM, Lakey JR and Shapiro AM: Five-year follow-up after clinical islet transplantation. Diabetes 54: 2060-2069, 2005.

6. Miyazaki S, Yamato E and Miyazaki J: Regulated expression of pdx-1 promotes in vitro differentiation of insulin-producing cells from embryonic stem cells. Diabetes 53: 1030-1037, 2004.

7. Kroon E, Martinson LA,Kadoya K, Bang AG, Kelly OG, Eliazer S, Young H, Richardson M, Smart NG, Cunningham J, et al: Pancreatic endoderm derived from human embryonic stem cells generates glucose-responsive insulin-secreting cells in vivo. Nat Biotechnol 26: 443-452, 2008.

8. Soria B, Skoudy A and Martin F: From stem cells to beta cells: New strategies in cell therapy of diabetes mellitus. Diabetologia 44: 407-415, 2001

9. Lumelsky N, Blondel O, Laeng P, Velasco I, Ravin R and McKay R: Differentiation of embryonic stem cells to insulin-secreting structures similar to pancreatic islets. Science 292: 1389-1394, 2001.

10. Krampera M,Franchini M,Pizzolo G and Aprili G: Mesenchymal stem cells: From biology to clinical use. Blood Transfus 5: 120-129, 2007.

11. Gimble JM, Katz AJ and Bunnell BA: Adipose-derived stem cells for regenerative medicine. Circ Res 100: 1249-1260, 2007.

12. Diaz-Prado S, Muiños-López E, Hermida-Gómez T, Cicione C Rendal-Vázquez ME, Fuentes-Boquete I, de Toro FJ and Blanco FJ: Human amniotic membrane as an alternative source of stem cells for regenerative medicine. Differentiation 81 : 162-171, 2011.

13. Gabr MM, Zakaria MM, Refaie AF, Khater SM, Ashamallah SA, Ismail AM, El-Halawani SM and Ghoneim MA: Differentiation of human bone marrow-derived mesenchymal stem cells into insulin-producing cells: Evidence for further maturation in vivo. Biomed Res Int 2015: 575837, 2015.

14. Sun Y, Zhang M, Ji S and Liu L: Induction differentiation of rabbit adipose-derived stromal cells into insulin-producing cells in vitro. Mol Med Rep 12: 6835-6840, 2015.

15. Kajiyama H, Hamazaki TS, Tokuhara M, Masui S, Okabayashi K, Ohnuma K, Yabe S, Yasuda K, Ishiura S,OkochiH and Asashima M: Pdx1-transfected adipose tissue-derived stem cells differentiate into insulin-producing cells in vivo and reduce hyperglycemia in diabetic mice. Int J Dev Biol 54: 699-705, 2010.

16. Okere B, Alviano F, Costa R, Quaglino D, Ricci F, Dominici M, Paolucci P, Bonsi L and Iughetti L: In vitro differentiation of human amniotic epithelial cells into insulin-producing 3D spheroids. Int J Immunopathol Pharmacol 28: 390-402, 2015.

17. Watanabe M, Yoneda M, Morohashi A, Hori Y, Okamoto D, Sato A, Kurioka D, Nittami T, Hirokawa Y, Shiraishi T, et al: Effects of $\mathrm{Fe}_{3} \mathrm{O}_{4}$ magnetic nanoparticles on A549 cells. Int J Mol Sci 14: 15546-15560, 2013.
18. Figuerola A, Di Corato R, Manna L and Pellegrino T: From iron oxide nanoparticles towards advanced iron-based inorganic materials designed for biomedical applications. Pharmacol Res 62: 126-143, 2010

19. Zhang D, Wang J, Wang Z, Wang R, Song L, Zhang T, Lin X, Shi $\mathrm{P}$, Xin $\mathrm{H}$ and Pang $\mathrm{X}$ : Polyethyleneimine-coated $\mathrm{Fe}_{3} \mathrm{O}_{4}$ nanoparticles for efficient siRNA Delivery to human mesenchymal stem cells derived from different tissues. Sci Adv Mater 7: 1058-1064, 2015

20. Hermanson O: Stem cells have different needs for Rest. PloS Biol 6: e271, 2008.

21. Johnson DS, Mortazavi A, Myers RM and Wold B: Genome-wide mapping of in vivo protein-DNA interactions. Science 316: 1497-1502, 2007

22. Martin D, Tawadros T, Meylan L, Abderrahmani A, Condorelli DF, Waeber G and Haefliger JA: Critical role of the transcriptional repressor neuron-restrictive silencer factor in the specific control of connexin36 in insulin-producing cell lines. J Biol Chem 278: 53082-53089, 2003.

23. Li B, Wang S, Liu H, Liu D, Zhang J, Zhang B, Yao H, Lv Y, Wang $\mathrm{R}$, Chen L, et al: Neuronal restrictive silencing factor silencing induces human amniotic fluid-derived stem cells differentiation into insulin-producing cells. Stem Cells Dev 20: 1223-1231, 2011

24. Li H, Jiang F, Shi P, Zhang T, Liu XY, Lin XW and Pang XN: In vitro reprogramming of rat bone marrow-derived mesenchymal stem cells into insulin-producing cells by genetically manipulating negative and positive regulators. Biochem Bioph Res Commun 420: 793-798, 2012.

25. Dayer D, Tabar MH, Moghimipour E, Tabandeh MR, Ghadiri AA, Bakhshi EA, Orazizadeh M and Ghafari MA: Sonic hedgehog pathway suppression and reactivation accelerates differentiation of rat adipose-derived mesenchymal stromal cells toward insulin-producing cells. Cytotherapy 19: 937-946, 2017.

26. Hebrok M, Kim SK and Melton DA: Notochord repression of endodermal Sonic hedgehog permits pancreas development. Genes Dev 12: 1705-1713, 1998.

27. Schwitzgebel VM, Mamin A, Brun T, Ritz-Laser B, Zaiko M, Maret A, Jornayvaz FR, Theintz GE, Michielin O, Melloul D and Philippe J: Agenesis of human pancreas due to decreased half-life of insulin promoter factor 1. J Clin Endocrinol Metab 88: 4398-4406, 2003.

28. Livak KJ and Schmittgen TD: Analysis of relative gene expression data using real-time quantitative PCR and the 2(-delta delta $\mathrm{C}(\mathrm{T})$ ) method. Methods 25: 402-408, 2001.

29. Yin H, Kanasty RL, Eltoukhy AA, Vegas AJ, Dorkin JR and Anderson DG: Non-viral vectors for gene-based therapy. Nat Rev Genet 15: 541-555, 2014

30. Allahverdi A, Abroun S, Jafarian A, Soleimani M, Taghikhani M and Eskandari F: Differentiation of human mesenchymal stem cells into insulin producing cells by using a lentiviral vector carrying PDX1. Cell J 17: 231-242, 2015.

31. Kemp DM, Lin JC and Habener JF: Regulation of Pax4 paired homeodomain gene by neuron-restrictive silencer factor. J Biol Chem 278: 35057-35062, 2003.

32. Li HT, Jiang FX, Shi P, Zhang T, Liu XY, Lin XW, San ZY and Pang XN: In vitro reprogramming of rat bmMSCs into pancreatic endocrine-like cells. In Vitro Cell Dev Biol Anim 53: 157-166, 2017. 